\title{
Restriction Fragment Length Polymorphisms of rRNA as Genetic Markers To Differentiate Chlamydia spp.
}

\author{
HIDETO FUKUSHI* AND KATSUYA HIRAI \\ Department of Veterinary Microbiology, Faculty of Agriculture, \\ Gifu University, Gifu 501-11, Japan
}

\begin{abstract}
Restriction fragment length polymorphisms (RFLPs) of rRNA genes of Chlamydia spp. were analyzed. A Southern analysis of chromosomal DNA digests with cloned rRNA gene probes revealed the presence of one locus for rRNA genes on chromosomal DNAs in Chlamydia psittaci, Chlamydia pecorum, and Chlamydia pneumoniae and two loci in Chlamydia trachomatis. The RFLPs of rRNA genes were characteristic for each Chlamydia sp. DNA probes cloned from flanking regions of the rRNA genes of avian $C$. psittaci hybridized either with only $C$. psittaci or with only the avian and ovine abortion strains of $C$. psittaci. The RFLPs of rRNA genes and the flanking regions provide suitable genetic markers for differentiation of Chlamydia spp.
\end{abstract}

Chlamydiae are obligatory intracellular bacteria which have a unique developmental cycle and manifest various pathogenicities (15). Currently, four species, Chlamydia trachomatis, Chlamydia psittaci, Chlamydia pneumoniae, and Chlamydia pecorum, are recognized within the genus Chlamydia $(7,10,15)$. C. trachomatis and C. pneumoniae are human pathogens, whereas $C$. psittaci and $C$. peconum are animal pathogens, although human infection can occur by contact with infected animals. Immunological and genetic analyses have revealed differences among avian and mammalian strains of $C$. psittaci and C. pecorum $(1,2,9,14,17$, 18).

We have been examining the immunological and genetic relationships among strains of $C$. psittaci for purposes of proper classification $(5,6,8)$. We previously described separation of $C$. psittaci strains into four groups and six types on the basis of DNA homology and restriction endonuclease digestion patterns. The DNA-DNA hybridization analysis showed that $C$. psittaci strains can be separated into two genetic groups, an avian-ovine abortion-feline group (group $\mathrm{Av}-\mathrm{Oa}-\mathrm{Fe}$ ) and a nonovine abortion ruminant group (group Ru). These two groups exhibit less than $20 \%$ intergroup DNA-DNA homology. We proposed establishment of a separate species for the group Ru of $C$. psittaci and named this taxon $C$. pecorum (7). C. pecorum infects primarily sheep and cattle and causes pneumonia, polyarthritis, encephalomyelitis, and diarrhea, but not ovine abortion, whereas $C$. psittaci includes a large variety of strains that infect various animals, including birds, ruminants, cats, guinea pigs, and koalas, and causes a variety of pathogenic effects in the host animals, including ovine abortion. Cumulative data indicate that strains belonging to group Av-Oa-Fe of $C$. psittaci may be placed in a separate species on the basis of differences in genetic properties and immunogenicity. Similarly, $C$. trachomatis strains can be divided into a human group (group $\mathrm{CtHu}$ ), which includes trachoma and lymphogranuloma venereum biovars, and a mouse group (group CtMo), which includes a mouse biovar. These two groups exhibit less than $40 \%$ intergroup homology $(6,11)$.

\footnotetext{
* Corresponding author.
}

In this report, we describe cloning of a region of rRNA genes conserved among Chlamydia spp. Using these genes as probes of chromosomal restriction digests, we found that C. psittaci, C. pecorum, and C. pneumoniae have one rRNA operon locus, while $C$. trachomatis has two loci. The restriction fragment length polymorphisms (RFLPs) of these regions were also analyzed and correlated with the classification of strains based on the results of a genomic DNA analysis (6). Our results indicate that the RFLPs are useful markers for identification and typing of Chlamydia spp.

The chlamydiae studied were 13 strains of $C$. psittaci, 5 strains of $C$. pecorum, 1 strain of $C$. pneumoniae, and 3 strains of $C$. trachomatis (Table 1). These strains have been described previously (5-8). Two additional strains, a guinea pig inclusion conjunctivitis strain of $C$. psittaci (strain ATCC VR813) (16) and $C$. pneumoniae $\mathrm{TW}_{183^{\mathrm{T}}}(\mathrm{T}=$ type strain) $(10,12)$, were also included. $C$. psittaci ATCC VR813 was shown to belong to group Av-Oa-Fe by Southern and DNADNA hybridization analyses (group Av-Oa-Fe-Gp) (data not shown). We used previously described procedures for cell culture growth of chlamydiae, purification of elementary bodies, and extraction of chlamydial DNA (5-7).

Molecular cloning, including plaque hybridization, and plasmid subcloning were performed by the methods described by Maniatis et al. (13). The host and vectors for molecular cloning were Escherichia coli DP50supF and TB1, phage lambda Charon 4A, and plasmid pUC19 (13). Genomic libraries were constructed with the lambda Charon $4 \mathrm{~A}$ vector. Cloned DNAs were subcloned into plasmid pUC19 and sequenced with a Sequenase version 2 kit (USB, Toyobo, Inc., Osaka, Japan) as recommended by the manufacturer.

Total RNA was extracted with an RNA extraction kit (Amersham Japan, Inc., Tokyo, Japan) from chlamydiainfected cells harvested $48 \mathrm{~h}$ after infection. RNA was electrophoresed by using the formaldehyde method (13) and was blotted onto a Hybond-N membrane (Amersham Japan, Inc.) by using a vacuum (VacuGene; Pharmacia LKB Biotechnology, Tokyo, Japan).

Agarose gel electrophoresis of DNA, vacuum transfer of nucleic acids, hybridization, and labeling of DNA probes with digoxigenin-dUTP (Boehringer Mannheim-Yamanouchi, Tokyo, Japan) were done as described previously $(4,6)$. Immunological detection of Southern and Northern (RNA) 
TABLE 1. Chlamydial strains used in this study

\begin{tabular}{|c|c|c|c|}
\hline Species & Fingerprint type $^{a}$ & Strain & Origin $^{b}$ \\
\hline \multirow[t]{14}{*}{ C. psittaci } & Av1a & $\begin{array}{l}\mathrm{Prt} / \mathrm{GCP}-1 \\
\mathrm{Hu} / \mathrm{Itoh} \\
\text { Tk/CA }\end{array}$ & $\begin{array}{l}\text { Parrot, systemic infection, Japan } \\
\text { Human, psittacosis, Japan } \\
\text { Turkey, ornithosis, United States }\end{array}$ \\
\hline & \multirow[t]{3}{*}{ Avlb } & Frt-Hu/Cal10 & Ferret-human, cold, United States \\
\hline & & Pgn/P1041 & Healthy pigeon, Japan \\
\hline & & Pgn/PCM69 & Pigeon, feces, Japan \\
\hline & \multirow[t]{4}{*}{ Avlc } & $\operatorname{Prk} / 6 \mathrm{BC}^{\mathrm{T}}\left(=\mathrm{ATCC}\right.$ VR125 $\left.5^{\mathrm{T}}\right)$ & Parakeet, United States \\
\hline & & Ckt/Okame & Cockatiel, systemic infection, Japan \\
\hline & & $\mathrm{Tk} / \mathrm{NJ}$ & Turkey, ornithosis, United States \\
\hline & & Hu/Borg (= ATCC VR601) & Human, psittacosis, United States \\
\hline & Av2a & Prk/Daruma & Parakeet, systemic infection, Japan \\
\hline & Av2b & Ov/B577 (= ATCC VR656) & Sheep, abortion, United States \\
\hline & \multirow[t]{3}{*}{$\mathrm{Fel}$} & $\mathrm{Fe} / \mathrm{Pn}-1(=$ ATCC VR120) & Cat, pneumonia, United States \\
\hline & & $\mathrm{Fe} / 145$ & Cat, conjunctivitis, United States \\
\hline & & Mu/M56 ( = ATCC VR630) & Muskrat, systemic infection, Canada \\
\hline & Gp1 & $\mathrm{Gp} / \mathrm{Ic}(=\mathrm{ATCC}$ VR813) & Guinea pig, inclusion conjunctivitis, United States \\
\hline \multirow[t]{5}{*}{ C. pecorum } & \multirow[t]{3}{*}{ Rula } & Bo/Yokohama & Cattle, enteric infection, Japan \\
\hline & & Bo/Maeda & Cattle, pneumonia, Japan \\
\hline & & Bo/Shizuoka & Cattle, encephalitis, Japan \\
\hline & Rulb & Ov/IPA (= ATCC VR629) & Sheep, polyarthritis, United States \\
\hline & Rulc & $\mathrm{Bo} / \mathrm{E}^{2} 8^{\mathrm{T}}\left(=\mathrm{ATCC}\right.$ VR628 $\left.{ }^{\mathrm{T}}\right)$ & Cattle, encephalitis, United States \\
\hline C. pneumoniae & CnTW & TW183 ${ }^{\mathrm{T}}$ & Human, conjunctiva, Taiwan \\
\hline \multirow{3}{*}{ C. trachomatis } & \multirow[t]{2}{*}{$\mathrm{CtHu}$} & $\mathrm{E} / \mathrm{UW}-5 / \mathrm{Cx}$ & Human, cervix, United States \\
\hline & & $\mathrm{L} 2 / 434 / \mathrm{Bu}^{\mathrm{T}}$ & Human, bubo, United States \\
\hline & CtMo & MoPn/Weiss-Nigg & Mouse, pneumonitis, United States \\
\hline
\end{tabular}

${ }^{a}$ Fingerprint (genetic) types were determined previously (6).

${ }^{b}$ Host (human, lower mammal, or bird), clinical condition or anatomic site, and/or geographic origin.

blots was performed with alkaline phosphatase-conjugated anti-digoxigenin antibody and the chemiluminescent substrate AMPPD (Boehringer Mannheim-Yamanouchi) by following the instructions in the manufacturer's manual.

Recombinant phages carrying conserved gene segments were cloned from genomic libraries of $C$. psittaci Prt/GCP-1 (genetic type Avla), Frt-Hu/Cal10 (genetic type Avlb), and Prk/Daruma (genetic type Av2a) by plaque hybridization with digoxigenin-labeled chromosomal DNA from $C$. trachomatis MoPn/Weiss-Nigg. The cloned region of the Frt$\mathrm{Hu} / \mathrm{Cal} 10$ DNA was $25.5 \mathrm{~kb}$ long and was derived from a single region (Fig. 1). Clones from Prt/GCP-1 and Prk/ Daruma, which were $25 \mathrm{~kb}$ long, produced similar physical maps (data not shown) and were derived from the region homologous to the cloned region of the Frt-Hu/Call0 library. Representative clones $\mathrm{c} 1$ and $\mathrm{cl} 4$ from the Frt-Hu/Cal10

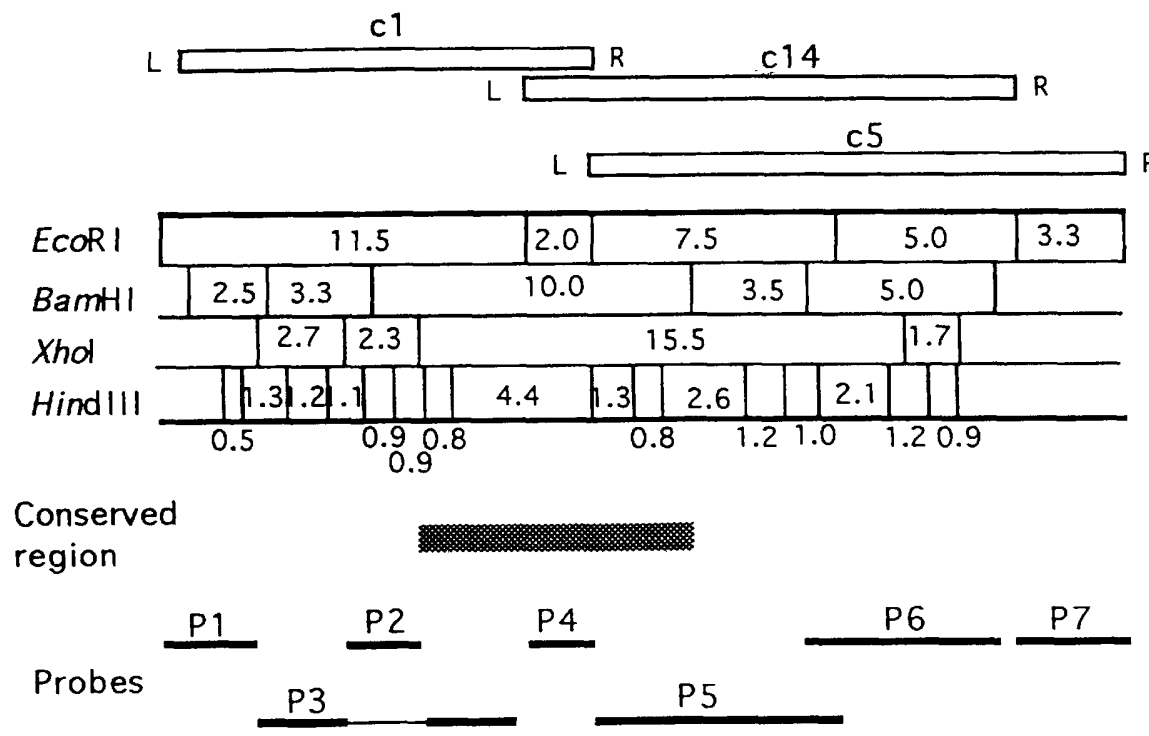

FIG. 1. Physical maps of the cloned regions carried by recombinant phages $\mathrm{c} 1, \mathrm{c} 14$, and $\mathrm{c} 5$. The cloned region was $25.5 \mathrm{~kb}$ long. The cross-hatched rectangle indicates the region hybridized with digoxigenin-dUTP-labeled chromosomal DNA of $C$. trachomatis $\mathrm{Ct} / \mathrm{MoPn}$. This region was bounded with XhoI and HindIII sites. The lines for probes P1 to P7 indicate the probe segments used for RFLP analysis in the experiments whose results are shown in Fig. 3 and Table 2. Probe 3 consisted of two separate fragments of the same size. 
A

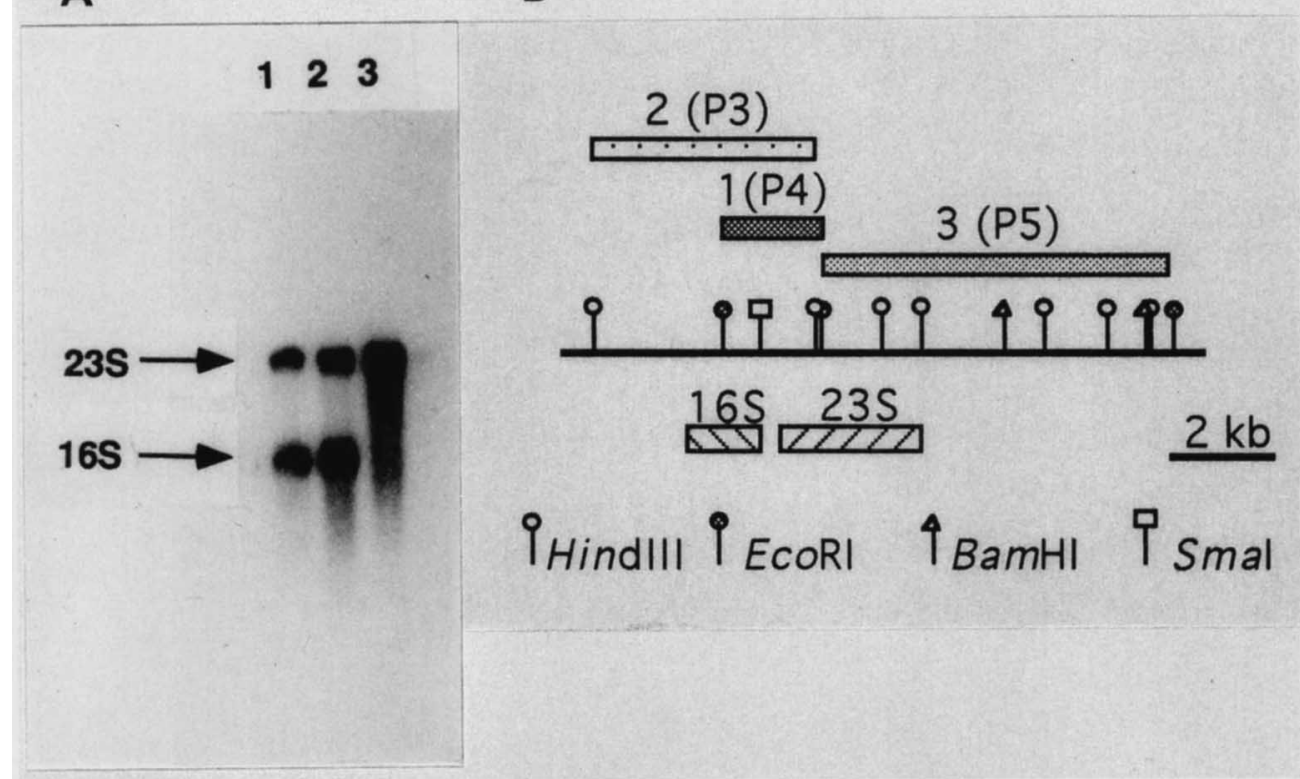

FIG. 2. Northern analysis performed with probes from the cloned segments of genes coding for rRNA (rDNA). (A) Northern blots of cloned segments. Lane 1, preparation probed with 2.0-kb EcoRI segment (segment 1); lane 2, preparation probed with 4.2-kb HindIII segment (segment 2); lane 3, preparation probed with 7.5-kb EcoRI segment (segment 3). (B) Physical map of rRNA gene showing the region analyzed, the location of each probe, and the endonuclease cleavage sites. Segments 1 to 3 were the probes used for the Northern analysis shown in panel A.

genomic DNA library and c5 from the Prt/GCP-1 genomic DNA library were used for the preparation of probes and for RFLP analysis (Fig. 1). Probes P1 to P4 were included in c1 DNA. Probe P3 contained $2.7 \mathrm{~kb}$ of separate XhoI and XhoI-EcoRI fragments; probes P5 and P6 were isolated from c14; and probe P7, which was isolated from $\mathrm{c5}$, was located next to probe P6.

The conserved region of Frt-Hu/Callo was located in an 8-kb segment, which contained a 2.0-kb EcoRI fragment (probe P4) in the middle of the region (Fig. 1). The portion of the P4 fragment that corresponded to the 16S rRNA gene was identical to the portion of the $3^{\prime}$ end of the 16S rRNA gene described by Weisburg et al. (19) (data not shown). A Northern analysis showed that cloned segments P3, P4, and P5 hybridized with $16 \mathrm{~S}$ and/or 23S rRNA (Fig. 2). These results indicated that the conserved region contained $16 \mathrm{~S}$ and $23 S$ rRNA genes.

We investigated the number of rRNA genes of Chlamydia spp., because Engel and Ganem (3) reported the presence of two rRNA genes in $C$. trachomatis $\mathrm{Ct} / \mathrm{MoPn}$, whereas the cloned ribosomal DNA segments of $C$. psittaci in this study were derived from one region. In addition, the restriction map of our cloned rRNA operon region was different from that of $C$. trachomatis $\mathrm{Ct} / \mathrm{MoPn}$ (3). A Southern analysis of SalI chromosomal digests with probe $\mathrm{P} 4$ revealed one hybridizing band, which was larger than $38 \mathrm{~kb}$, for C. psittaci, $C$. peconum, and $C$. pneumoniae DNAs and two hybridizing bands for $C$. trachomatis (15 and $17.5 \mathrm{~kb}$ for the group $\mathrm{CtHu}$ strain and 18 and $36 \mathrm{~kb}$ for the group CtMo strain) (Fig. 3A). Southern analyses of fingerprints performed with other enzymes, including KpnI, which did not cut within the cloned 25- to 25.5-kb region of Frt-Hu/Cal10, Prt/GCP-1, and Prk/ Daruma, and with probes of flanking segments (P3 and P5) also revealed one hybridizing band for $C$. psittaci, $C$. peco- num, and $C$. pneumoniae and two segments for $C$. trachomatis (data not shown).

RFLPs within the rRNA gene operon were also investigated. The sizes of the hybridizing segments correlated with the genetic types determined previously. In the case of EcoRI fingerprints, probe $\mathrm{P} 4$ hybridized with a $2.0-\mathrm{kb}$ EcoRI restriction fragment of $C$. psittaci, $C$. pecorum, or $C$. pneumoniae DNA and with two EcoRI fragments of human and mouse strains of $C$. trachomatis (5.6 and $7.4 \mathrm{~kb}$ for the group $\mathrm{CtHu}$ strain and 4.6 and $7.0 \mathrm{~kb}$ for the group CtMo strain) (Fig. 3B and Table 2). Probes containing the $5^{\prime}$ part of the 16S rRNA gene (probe P3) or the $3^{\prime}$ part of the 23S rRNA gene (probe P5) hybridized with fragments consistent with the genetic types previously determined by DNA fingerprinting of chromosomal DNAs (Fig. $3 \mathrm{C}$ and Table 2). The EcoRI site in the 23S rRNA gene seemed to be conserved within the genus Chlamydia, whereas other restriction sites, including the EcoRI site in the 16S rRNA gene, showed variation.

On the other hand, probes of flanking regions hybridized with specific genetic types. Probe P2, containing segments upstream of the 16S rRNA gene, and probe P7, situated further downstream from the 23S rRNA gene, hybridized only with $C$. psittaci strains; probe P1, situated upstream of probe $\mathrm{P} 2$, and probe $\mathrm{P} 6$, situated between the 23S rRNA gene and probe $\mathrm{P} 7$, hybridized with avian and ovine abortion strains of $C$. psittaci but not with feline and guinea pig strains of $C$. psittaci, and strains of $C$. pecorum, $C$. pneumoniae, and $C$. trachomatis.

In summary, our results indicated that $C$. psittaci, $C$. peconum, and $C$. pneumoniae have one copy of the rRNA operon and $C$. trachomatis has two copies. Previously, Engel and Ganem (3) and Palmer et al. (17) reported that Chlamydia spp. have two rRNA gene loci on the basis of the 


\section{A}

12345678910111213

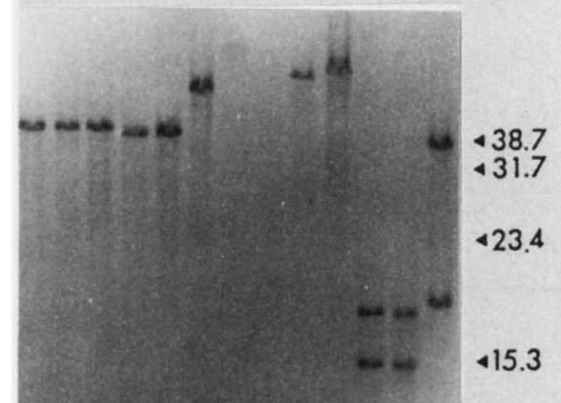

412.7

49.2

47.2
B

1234567891011121314

C
123455678910111213

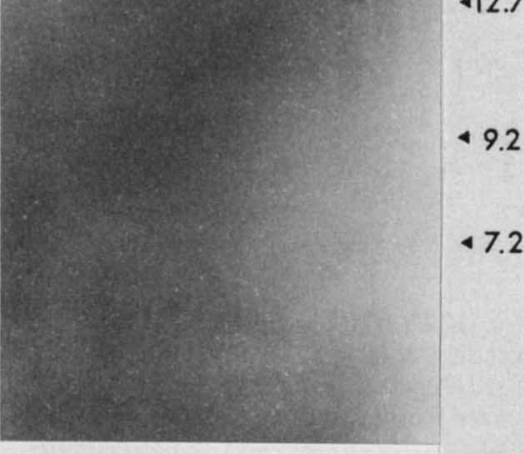

FIG. 3. RFLP analysis of Chlamydia spp. Southern blots of SalI digests (A) and EcoRI digests (B and C) were hybridized with 2.0-kb EcoRI probe P4 (A and B) or 7.5-kb EcoRI probe P5 (C) of c14 cloned segments. The digested DNAs were electrophoresed in a $0.5 \%$ (A), $0.8 \%$ (B), or $0.7 \%$ (C) agarose gel and blotted onto a nylon membrane. The Southern blots prepared with P4 revealed one hybridized fragment for $C$. psittaci, $C$. pecorum, and $C$. pneumoniae and two fragments for $C$. trachomatis. The sizes of the hybridized fragments varied within each genetic type. (A and C) Lanes 1 to 6 and lane 9, C. psittaci; lanes 7 and 8, C. pecorum; lane 10, C. pneumoniae; lanes 11 to $13, C$. trachomatis. Lane 1, genetic type Avla strain Prt/GCP-1; lane 2, genetic type Avlb strain Frt-Hu/Cal10; lane 3, genetic type Avlc strain Prk/6BC ${ }^{\mathrm{T}}$ (= ATCC VR125 $)$; lane 4, genetic type Av2a strain Prk/Daruma; lane 5, genetic type Av2b strain Ov/B577 (= ATCC VR656); lane 6, genetic type Fe1 strain Fe/Pn-1 (= ATCC VR120); lane 7, genetic type Ru1 strain Bo/Maeda; lane 8, genetic type Ru strain Bo/Shizuoka; lane 9, genetic type Gp1 strain Gp/Ic (= ATCC VR813); lane 10, genetic type CnTW strain TW183 ${ }^{\mathrm{T}}$; lane 11 , genetic type CtHu strain E/UW-5/Cx; lane 12, genetic type CtHu strain L2/434/Bu ${ }^{\mathrm{T}}$; lane 13, genetic type CtMo strain MoPn/Weiss-Nigg. (B) Lanes 1 to 7 and lane $10, C$. psittaci; lanes 8 and 9, C. pecorum; lane 11, C. pneumoniae; lanes 12 to 14, $C$. trachomatis. Lane 1, genetic type Avla strain Prt/GCP-1; lane 2, genetic type Avlb strain Frt-Hu/Cal10; lane 3, genetic type Avlc strain Prk/6BC ${ }^{\mathrm{T}}$ (= ATCC VR125 ); lane 4, genetic type Av2a strain Prk/Daruma; lane 5, genetic type Av2b strain Ov/B577 (= ATCC VR656); lane 6, genetic type Fe1 strain Fe/Pn-1 (= ATCC VR120); lane 7, genetic type Fe1 strain Mu/M56 (= ATCC VR630); lane 8, genetic type Rul strain Bo/Maeda; lane 9, genetic type Rul strain Bo/Shizuoka; lane 10, genetic type Gp1 strain Gp/Ic (= ATCC VR813); lane 11, genetic type CnTW strain TW183 ${ }^{\mathrm{T}}$; lane 12, genetic type CtMo strain $\mathrm{MoPn} / \mathrm{Weiss}-\mathrm{Nigg}$; lane 13, genetic type CtHu strain E/UW-5/Cx; lane 14, genetic type CtHu strain $\mathrm{L} 2 / 434 / \mathrm{Bu}^{\mathrm{T}}$. The arrowheads and numbers indicate the positions and sizes (in kilobases) of marker fragments. The marker fragments were digoxigenin-dUTP-labeled bacteriophage T4 DNA fragments restricted with SalI (A) and phage lambda DNA fragments restricted with HindIII (B and C).

observation that $C$. trachomatis MoPn and $C$. psittaci $\mathrm{Gp} / \mathrm{Ic}$ produced two EcoRI bands which hybridized to the labeled 16S rRNA probe. Our results also showed that the probe containing the 16S rRNA gene hybridized with two EcoRI segments of $C$. psittaci DNA. However, this finding was expected, because an EcoRI site was present within the 16S rRNA genes of $C$. psittaci, $C$. pecorum, and $C$. pneumoniae, but not in $C$. trachomatis. These findings imply that rRNA genes are single-copy components in the $C$. psittaci, $C$. pecorum, and $C$. pneumoniae genomes, in contrast to the $C$. trachomatis genome, which has two copies. If the rRNA genes are multicopy genes in these three species, they must be within highly conserved repeated units more than $40 \mathrm{~kb}$ long. It is interesting that this genetic characteristic corresponded to phenotypic characteristics of the species, including the presence of glycogen deposits, the morphology of inclusions, and sulfadiazine resistance.

The classification data based on RFLP and DNA hybrid- ization results obtained with probes derived from rRNA flanking regions were in agreement with our previous genetic grouping and typing data. In particular, the hybridization patterns for probes $\mathbf{P} 2$ and $\mathbf{P} 7$ from the flanking regions are consistent with the genetic differentiation of $C$. pecorum from avian, ovine abortion, feline, and guinea pig (group Av-Oa-Fe-Gp) strains of $C$. psittaci.

These results suggest that the RFLPs of rRNA gene loci may be used as genetic markers for identification of Chlamydia species. Furthermore, it should be possible to choose genus-, species-, or type-specific probes and primer sequences from these rRNA gene loci and their flanking regions for hybridization and polymerase chain reaction assays for detection and determination of genetic types of chlamydiae.

Sequencing of the rRNA operons of ovine abortion, feline, and guinea pig strains of $C$. psittaci and strains of $C$. pecorum may provide information regarding the genetic 
TABLE 2. EcoRI fragments of genomic DNAs of Chlamydia spp. hybridized with cloned ribosomal DNA probes of avian $C$. psittaci containing conserved and flanking regions

\begin{tabular}{|c|c|c|c|c|c|c|c|c|c|}
\hline \multirow{2}{*}{ Species } & \multirow{2}{*}{ Genetic type } & \multirow{2}{*}{ Strain } & \multicolumn{7}{|c|}{ Fragment sizes $(\mathrm{kb})$ with the following probes ${ }^{a}$ : } \\
\hline & & & P1 & $\mathbf{P 2}$ & P3 & P4 & P5 & P6 & P7 \\
\hline \multirow[t]{7}{*}{ C. psittaci } & Avla & Prt/GCP-1 & 21.0 & 21.0 & 21.0 & 2.0 & 12.5 & 12.5 & 3.3 \\
\hline & Avlb & Frt-Hu/Cal10 & 11.5 & 11.5 & 11.5 & 2.0 & 7.5 & $5.0,7.5$ & 3.3 \\
\hline & Avlc & Prk/6BC & 21.0 & 21.0 & 21.0 & 2.0 & 12.5 & 12.5 & 3.3 \\
\hline & Av2a & Prk/Daruma & 21.0 & 21.0 & 21.0 & 2.0 & 12.5 & 12.5 & 2.4 \\
\hline & Av2b & Ov/B577 & 21.0 & 21.0 & 21.0 & 2.0 & 12.5 & 12.5 & 2.4 \\
\hline & Fe1 & $\mathrm{Fe} / \mathrm{Pn}-1$ & $-^{b}$ & 8.6 & $8.6,2.05$ & 2.0 & 7.0 & - & $7.0,6.2$ \\
\hline & Gp1 & $\mathrm{Gp} / \mathrm{Ic}$ & - & 2.6 & 2.6 & 2.0 & 11.0 & - & 2.4 \\
\hline \multirow[t]{2}{*}{ C. pecorum } & Rula & Bo/Shizuoka & - & - & 4.0 & 2.0 & 4.0 & - & - \\
\hline & Rulc & $\mathrm{Bo} / \mathrm{E} 58^{\mathrm{T}}$ & - & - & 4.0 & 2.0 & 3.8 & - & - \\
\hline C. pneumoniae & CnTW & TW183 & - & - & 2.8 & 2.0 & 5.4 & - & - \\
\hline \multirow[t]{2}{*}{ C. trachomatis } & CtMo & MoPn/Weiss-Nigg & - & - & $7.0,4.6$ & $7.0,4.6$ & $8.7,3.85$ & - & - \\
\hline & $\mathrm{CtHu}$ & E/UW-5/Cx & - & - & $7.4,5.6$ & $7.4,5.6$ & 3.2 & - & - \\
\hline
\end{tabular}

${ }^{a}$ The probes were a 3.8-kb XhoI-EcoRI fragment (P1), a 2.3-kb XhoI fragment (P2), a mixture of a 2.7-kb XhoI fragment and a XhoI-EcoRI fragment (P3), a 2.0-kb EcoRI fragment (P4), a 7.6-kb EcoRI fragment (P5), a 5.0-kb BamHI fragment (P6), and a 3.3-kb EcoRI fragment (P7). Probes P1 through P6 were cloned from a genetic type Avlb strain Frt-Hu/Cal10 library; probe P7 was cloned from a genetic type Avla strain Prt/GCP-1 library.

$b$-, no signal was detected.

distances of these chlamydial strains from each other. The results of analyses of rRNA genes, especially $16 \mathrm{~S}$ and $5 \mathrm{~S}$ rRNAs genes, have been used as indicators of phylogenic relatedness among bacteria (20). Therefore, the sequences of the rRNA genes and other genes of these strains may be useful for determining the phylogenic relationships of these organisms within the genus Chlamydia.

\section{ACKNOWLEDGMENTS}

We thank Cho-Chou Kuo and Lee Ann Campbell for helpful comments and suggestions during the preparation of the manuscript.

This research was supported in part by Grants-in-Aid for Scientific Research from the Ministry of Education, Science and Culture of Japan.

\section{REFERENCES}

1. Anderson, A. A. 1991. Serotyping of Chlamydia psittaci isolates using serovar-specific monoclonal antibodies with the microimmunofluorescence test. J. Clin. Microbiol. 29:707-711.

2. Campbell, L. A., C.-C. Kuo, and J. T. Grayston. 1987. Characterization of the new Chlamydia agent, TWAR, as a unique organism by restriction endonuclease analysis and DNA-DNA hybridization. J. Clin. Microbiol. 25:1911-1916.

3. Engel, J. N., and D. Ganem. 1987. Chlamydial rRNA operons: gene organization and identification of putative tandem promoters. J. Bacteriol. 169:5678-5685.

4. Feinberg, A. P., and B. Vogelstein. 1983. A technique for radio-labeling DNA restriction endonuclease fragments to high specific activity. Anal. Biochem. 132:6-13.

5. Fukushi, H., and K. Hirai. 1988. Immunochemical diversity of the major outer membrane protein of avian and mammalian Chlamydia psittaci. J. Clin. Microbiol. 26:675-680.

6. Fukushi, H., and K. Hirai. 1989. Genetic diversity of avian and mammalian Chlamydia psittaci strains and relation to host origin. J. Bacteriol. 171:2850-2855.

7. Fukushi, H., and K. Hirai. 1992. Proposal of Chlamydia peconum sp. nov. for Chlamydia strains derived from ruminants. Int. J. Syst. Bacteriol. 42:306-308.

8. Fukushi, H., K. Nojiri, and K. Hirai. 1987. Monoclonal antibody typing of Chlamydia psittaci derived from avian and mammalian species. J. Clin. Microbiol. 25:1978-1981.

9. Girjes, A. A., A. F. Hugall, P. Timms, and M. T. Lavin. 1988. Two distinct forms of Chlamydia psittaci associated with disease and infertility in Phascolarctos cinereus (koala). Infect. Immun. 56:1897-1900.

10. Grayston, J. T., C. C. Kuo, L. A. Campbell, and S. P. Wang. 1989. Chlamydia pneumoniae sp. nov. for Chlamydia sp. strain TWAR. Int. J. Syst. Bacteriol. 39:88-90.

11. Kingsbury, D. T., and E. Weiss. 1968. Lack of deoxyribonucleic acid homology between species of the genus Chlamydia. J. Bacteriol. 96:1421-1423.

12. Kuo, C.-C., H. Cheu, S. Wang, and J. T. Grayston. 1986. Identification of a new group of Chlamydia psittaci strains called TWAR. J. Clin. Microbiol. 24:1034-1037.

13. Maniatis, T., E. F. Fritsch, and J. Sambrook. 1982. Molecular cloning: a laboratory manual. Cold Spring Harbor Laboratory, Cold Spring Harbor, N.Y.

14. McClenaghan, M., A. J. Herring, and I. D. Aitken. 1984. Comparison of Chlamydia psittaci isolates by DNA restriction endonuclease analysis. Infect. Immun. 45:384-389.

15. Moulder, J. W., T. P. Hatch, C.-C. Kuo, J. Schachter, and J. Storz. 1984. Chlamydia Jones, Rake and Stearns 1945, p. 729-735. In N. R. Krieg and J. G. Holt (ed.), Bergey's manual of systematic bacteriology, vol. 1. The Williams \& Wilkins Co., Baltimore.

16. Murray, E. S. 1964. Guinea pig inclusion conjunctivitis virus. I. Isolation and identification as a member of the psittacosislymphogranuloma-trachoma group. J. Infect. Dis. 114:1-12.

17. Palmer, L., S. Falkow, and L. Klevan. 1986. 16S ribosomal RNA genes of Chlamydia trachomatis, p. 89-92. In D. Oriel, G. Ridgway, J. Schachter, D. Taylor-Robinson, and M. Ward (ed.), Chlamydial infections. Cambridge University Press, Cambridge.

18. Timms, P., F. W. Eaves, A. A. Girjes, and M. F. Lavin. 1988. Comparison of Chlamydia psittaci isolates by restriction endonuclease and DNA probe analyses. Infect. Immun. 56:287-290.

19. Weisburg, W. G., T. P. Hatch, and C. R. Woese. 1986. Eubacterial origin of chlamydiae. J. Bacteriol. 167:570-574.

20. Woese, C. R. 1987. Bacterial evolution. Microbiol. Rev. 51:221271. 